\title{
Adeline Rucquoi, (dir.), Saint-Jacques et la France, Actes du Colloque des 18/19 janvier 2001 à la Fondation Singer-Polignac
}

\section{Sophie Cassagnes-Brouquet}

\section{(2) OpenEdition Journals}

Édition électronique

URL : http://journals.openedition.org/abpo/1439

DOI : 10.4000/abpo.1439

ISBN : 978-2-7535-1490-4

ISSN : $2108-6443$

\section{Éditeur}

Presses universitaires de Rennes

\section{Édition imprimée}

Date de publication : 20 juillet 2003

Pagination : 244-245

ISBN : 978-2-86847-874-0

ISSN : $0399-0826$

\section{Référence électronique}

Sophie Cassagnes-Brouquet, « Adeline Rucquoi, (dir.), Saint-Jacques et la France, Actes du Colloque des 18/19 janvier 2001 à la Fondation Singer-Polignac ", Annales de Bretagne et des Pays de l'Ouest [En ligne], 110-2 | 2003, mis en ligne le 20 juillet 2005, consulté le 23 septembre 2020. URL : http:// journals.openedition.org/abpo/1439; DOI : https://doi.org/10.4000/abpo.1439 
fabrication plus facile, des objets de meilleure qualité et plus nombreux " (p. 37 et suiv.), tout comme les importantes commandes passées par certains souverains, dont Philippe le Bel, laissaient espérer des chiffres globaux plus élevés.

Hervé MARTIN

Rucquol, Adeline (dir.), Saint-Jacques et la France, Actes du Colloque des 18/19 janvier 2001 à la Fondation Singer-Polignac, Paris, Le Cerf, 2003.

Réunies à l'occasion du cinquantenaire de la Société des Amis de Saint-Jacques-de-Compostelle, deux journées d'études ont permis la confrontation d'historiens médiévistes français et espagnols sur le thème des relations de la France et de SaintJacques en Galice, une rencontre particulièrement fructueuse qui s'est traduite par la publication d'un volume d'actes aussi dense que riche.

Jean Mesnard introduit les contributions des participants par une passionnante enquête sur la réflexion d'Alphonse Dupront sur le fait pèlerin en direction de Compostelle. Tout en montrant combien sa démarche demeure d'actualité, il annonce les quatre parties qui ont rythmé les réflexions des participants, transcrites en termes simples, mais particulièrement évocateurs : vénérer, représenter, écrire et agir.

Trois contributions apportent différents éclairages sur le culte de saint Jacques au nord des Pyrénées : en Alsace (Vicente Almazan), à Paris, à travers l'étude des registres de la confrérie de saint Jacques (Annie Saunier) et, enfin, grâce à l'analyse des enseignes de pèlerinage découvertes sur la via tolosana (Denis Bruna).

Le culte s'adosse en effet à l'image, c'est l'objet de la deuxième partie de l'ouvrage : « Représenter ».

Elle débute par une étude très riche d'Humbert Jacomet sur l'iconographie de saint Jacques en France qui fait le point avec beaucoup de précision les particularités de l'image française et comment s'impose peu à peu la représentation du saint en pèlerin. Anne Prache reprend et renouvelle le dossier déjà ancien de l'architecture des églises de pèlerinage sur la route de Saint-Jacques, tandis que Francesca Espanol et Marisa Melero-Moneo se penchent sur l'iconographie espagnole de deux saints français présents sur les routes de Compostelle, saint Léonard et saint Saturnin.

L'analyse des textes permet aussi de monter combien le culte de saint Jacques est omniprésent en France tant dans l'Épître préliminaire du Liber sancti Jacabi (Manuel C. Diaz y Diaz), que dans les chansons de geste françaises et chez les poètes (Pierre-Gilles Girault et Michel Zink). Nicole Bériou et Marie-Anne Polo de Beaulieu analysent la présence du pèlerinage à Compostelle dans les sermons des prédicateurs et les exempla.

La dernière partie intitulée "Agir " évoque les liens étroits noués entre Cluny et SaintJacques de Compostelle (Patrick Henriet) et l'implantation de l'ordre de Santiago en France (Philippe Josserand). La réalité matérielle du pèlerinage est décrite par une étude fouillée de Jean Glénisson sur le chemin entre Pons et Blaye et l'hôpital neuf de Pons (Pascal Even). Enfin, Francis Rapp évoque la transition avec l'époque moderne en analysant l'attitude des humanistes et des réformateurs en Alsace face au pèlerinage.

Comme le souligne Adeline Rucquoi dans sa conclusion, la richesse et la diversité des contributions font la démonstration de l'existence d'un saint 
Jacques français distinct par le nombre de ses chapelles et de ses autels, par son iconographie bien particulière et ses légendes. Saint Jacques de Galice a réellement envahi l'espace français et les mentalités religieuses. Il était donc tout à fait justifié de lui consacrer ce précieux volume qui fera date dans l'histoire de la recherche sur Compostelle.

Sophie CASSAGnes-BRouQueT

GUENEE, Bernard, L'opinion publique à la fin du Moyen Âge d'après la "Chronique de Charles VI » du Religieux de Saint-Denis, Paris, Perrin, 2002, 270 pages.

Depuis une vingtaine d'années, Bernard Guénée, éminent spécialiste de l'histoire politique du bas Moyen Âge et de l'historiographie médiévale, est aussi le chercheur français le mieux informé sur le règne de Charles VI et sur la "Chronique du Religieux de Saint-Denis " qui lui est consacrée. Il y a trois ans, j'ai rendu compte ici même de Un roi et son historien. Vingt études sur le règne de Charles VI et la "Chronique du Religieux de Saint-Denis ", une splendide série d'articles, d'une érudition raffinée. Cette fois, le propos, moins savant tout en restant très riche, ne s'adresse plus à un cénacle restreint de confrères et de disciples, mais à un public plus large, pour lequel Bernard Guénée a conçu un dosage subtil de sémantique historique et de narration événementielle.

La source essentielle du présent ouvrage, comme du précédent, est donc cette fameuse Chronique de Charles VI, écrite en latin par un religieux de l'abbaye de Saint-Denis longtemps resté anonyme. On sait aujourd'hui qu'il s'appelait Michel Pintoin, qu'il a vécu entre 1349 et 1421, et qu'il a exercé un temps les fonctions de chantre dans sa communauté. Il se montre souvent attentif à la façon dont "l'opinion publique ", ou ce qui en tient lieu à son époque, réagit aux événements, d'où le titre choisi par Bernard Guénée, qui taille d'ailleurs un peu large. D'entrée de jeu, le spécialiste de l'État bas-médiéval nous fournit deux exemples assez convaincants de la façon dont Michel Pintoin expose l'éventail des réactions à un événement donné. En 1386, l'annulation du projet de débarquement en Angleterre, longuement mûri par le roi et son entourage, suscite des mouvements divers. En 1405, l'opposition conjuguée du bon peuple, des sages et du conseil du roi empêche le duc Louis d'Orléans de s'emparer du gouvernement et des revenus du duché de Normandie. Ces observations faites par le chroniqueur n'ont, évidemment, rien à voir avec les façons modernes de suivre les fluctuations de l'opinion publique. Le savant bénédictin ne s'exprime pas avec des chiffres, mais avec des mots, avec des termes latins bien frappés qui, à tout prendre, valent bien nos fastidieux sondages, souvent destinés à dévoiler l'accessoire pour mieux cacher l'essentiel!

Dans le cadre restreint de ce compte rendu, nous ne pouvons entrer dans le détail des analyses lexicographiques conduites par l'auteur pour cerner l'état de l'opinion publique sous Charles VI et, plus largement, le système culturel de représentations concernant la communauté politique française, les différents états de la société et l'affirmation d'une élite dans l'État, les villes et le clergé. Ce genre d'études tout en nuances se savoure mais ne saurait se résumer. $\mathrm{La}$ méthose utilisée est d'inspiration socio-linguistique. Tout repose sur la statistique lexicale, considérée comme la meilleure porte d'entrée possible pour cerner les représentations collectives. Il est effectivement essentiel de connaître le nombre d'occurrences de populus, bonum commune, regnicole, publica utilitas, 